\title{
Letter to the editor: Applying incidence-based disability- adjusted life years (DALYs) disease burden estimates to foster change in national vaccination policy, Slovenia, 2017 to 2018
}

Mario Fafangel ${ }^{1}$, Marta Grgič Vitek ${ }^{1}$, Irena Klavs ${ }^{1}$

1. National Institute of Public Health (NIJZ), Ljubljana, Slovenia

Correspondence: Mario Fafangel (mario.fafangel@nijz.si)

Citation style for this article:

Fafangel Mario, Grgič Vitek Marta, Klavs Irena. Letter to the editor: Applying incidence-based disability-adjusted life years (DALYs) disease burden estimates to foster change in national vaccination policy, Slovenia, 2017 to 2018 . Euro Surveill. 2018;23(27): pii=1800354. https://doi.org/10.2807/1560-7917.

ES.2018.23.27.1800354

To the editor: Recently, Cassini et al. presented in Eurosurveillance the results of the burden of infectious diseases in European Union and European Economic Area (EU/EEA) countries [1], using the incidence-based methodology to calculate disability-adjusted life years (DALYS) developed within the Burden of Communicable Diseases in Europe (BCoDE) project [2]. The description of the impact of diseases on the health of the population by means of a composite health measure provides clear and comprehensive information for transparent and accountable decision-making. Thus, measures such as DALYs have the potential to play a significant role in health policy formulation.

We wish to add our first-hand experience using the BCoDE incidence-based approach to foster change in national vaccination policies. In a study published in 2017, based on the same methodology, we estimated the burden of tick-borne encephalitis (TBE) in Slovenia [3]. Compared with other EU/EEA countries, notification rate of TBE in Slovenia is among the highest, ranging from eight per 100,000 population in 2009 to 15 per 100,000 population in 2013 [4]. In terms of burden, we estimated that TBE in Slovenia during 2009-2013 accounted annually for 11.0 DALYs per 100,000 population (95\% uncertainty interval (UI): 10.2-11.7), much higher than the pooled results published by Cassini et al. for selected EU countries (including Slovenia) in the same time period, which was 0.69 DALYs per 100,000 population (95\% UI: $0.65-0.74)$ [1,3]

Vaccination against TBE has to be paid out of pocket for the majority of the population (except for occupationally exposed persons), with overall coverage remaining low at $7 \%$ [5]. With limited resources hindering the ability to offer universal and free TBE vaccination to the general population, evidence was needed for targeting vaccination to groups where the disease impact is highest, in order to yield the greatest benefit for the health of the population. Incidence of TBE in Slovenia was highest in the 50-74 years age group; however, we identified the highest burden of TBE among children aged 5-14 years. We concluded that incidence alone did not fully reflect the impact of disease and advised to complement epidemiological information with burden of disease estimates to inform vaccination policy.

Based on our results, a proposal for TBE vaccination policy change was on the agenda at our National Immunisation Technical Advisory Group (NITAG) on 15 June 2016 [6]. Our results, in addition to other factors such as routine surveillance data, specifics of the national immunisation programme linked to implementation of vaccination and expert opinions of specialists at the National Institute of Public Health (NIJZ) were considered by NITAG. Together they led NITAG to advise the introduction of publicly reimbursed TBE vaccination for children at 3 years of age and for adults at 45-50 years of age. The respective proposal prepared by NIJZ was considered by the Health Council at the Ministry of Health and approved on 10 May 2017 [7]. At the time of writing, negotiations are ongoing to ensure funding to implement the decision in 2019.

In our experience, the use of the methodology and toolkit developed by Cassini et al. provided a comprehensive view of the burden of disease on population health and helped us identify priority groups for intervention [8]. The disability-related impact of TBE on different age groups would not have been detected if we had limited our assessment to incidence alone, thus ignoring the combined effects of morbidity, short- and long-term sequelae and mortality, which are taken into account in the proposed BCoDE methodology. In our 
opinion, such an approach could benefit other EU/EEA countries by providing evidence-based information that allows for national and international comparisons, effective priority ranking of communicable diseases for public health action, identification of risk groups and a straightforward indicator to communicate public health needs to policymakers.

\section{Conflict of interest}

None declared.

Authors' contributions

All authors contributed equally to the letter.

\section{References}

1. Cassini A, Colzani E, Pini A, Mangen M-JJ, Plass D, McDonald SA, et al. On Behalf of The BCoDE Consortium. Impact of infectious diseases on population health using incidencebased disability-adjusted life years (DALYs): results from the Burden of Communicable Diseases in Europe study, European Union and European Economic Area countries, 2009 to 2013. Euro Surveill. 2018;23(16):17-00454. https:// doi.org/10.2807/1560-7917.ES.2018.23.16.17-00454 PMID: 29692315

2. Kretzschmar $M$, Mangen $M-J J$, Pinheiro $P$, Jahn B, Fèvre EM, Longhi S, et al. BCoDE consortium. New methodology for estimating the burden of infectious diseases in Europe. PLoS Med. 2012;9(4):e1001205. https://doi.org/10.1371/journal. pmed.1001205 PMID: 22529750

3. Fafangel M, Cassini A, Colzani E, Klavs I, Grgič Vitek M, Učakar V, et al. Estimating the annual burden of tick-borne encephalitis to inform vaccination policy, Slovenia, 2009 to 2013. Euro Surveill. 2017;22(16):30509. https://doi. org/10.2807/1560-7917.ES.2017.22.16.30509 PMID: 28449731

4. Grgič-Vitek M, Klavs I. High burden of tick-borne encephalitis in Slovenia--challenge for vaccination policy. Vaccine. 2011;29(32):5178-83. https://doi.org/10.1016/j. vaccine.2011.05.033 PMID: 21620916

5. Učakar V, Jeraj I, Grgič-Vitek M, Kraigher A. Analiza izvajanja cepljenja v Sloveniji v letu 2016. [Vaccination report for Slovenia in 2016]. Ljubljana: NIJZ; 2018. [Slovenian]. Available from: http://www.nijz.si/sites/www.nijz.si/files/uploaded/ porocilo_cepljenje2016.pdf

6. National advisory committee on immunization - Slovenia (NITAG). Meeting minutes. Ljubljana: National Institute of Public Health; 15 Jun 2016. [Slovenian]. Available from: http:// nijz.si/sites/www.nijz.si/files/uploaded/zapis_sestanka_ pSC_15062016.pdf

7. Health Council - Slovenia. Meeting minutes. Ljubljana: Ministry of Health; 10 May 2017. [Slovenian]. Available from: http://www.mz.gov.si/fileadmin/mz.gov.si/ pageuploads/zdravstveni_svet/ZS_2017/zapisniki_2017/ zapisnik_4_2017_seje_ZS.pdf

8. Colzani E, Cassini A, Lewandowski D, Mangen M-JJ, Plass D, McDonald SA, et al. A Software Tool for Estimation of Burden of Infectious Diseases in Europe Using IncidenceBased Disability Adjusted Life Years. Olson DR, editor. PLoS One. 2017;12(1):e0170662. https://doi.org/10.1371/journal. pone.0170662 PMID:28107447.

\section{License and copyright}

This is an open-access article distributed under the terms of the Creative Commons Attribution (CC BY 4.0) Licence. You may share and adapt the material, but must give appropriate credit to the source, provide a link to the licence, and indicate if changes were made.

This article is copyright of the authors or their affiliated institutions, 2018. 